\section{Screening of $\beta$-thalassemia trait among pregnant women with NESTROFT}

\author{
Hitesh Sarda, Shankaran Rukmini \\ Niveditha, Nirmala Shivlingaiah
}

Department of Pathology, Kempegowda Institute of Medical Sciences, Bangalore, Karnataka, India

\section{Abstract}

The morbidity of $\beta$-thalassemia major has forced medical professionals to formulate screening tests to effectively screen $\beta$-thalassemia trait (BTT) of which naked eye single tube osmotic fragility test (NESTROFT) is the most cost effective test. Optimal time to screen for BTT appears to be during pregnancy, as at risk couples can be offered prenatal diagnosis. We screened 55 pregnant women attending antenatal clinic in a medical college hospital at Bangalore, with NESTROFT. Twelve (21.89\%) were NESTROFT positive with mean hemoglobin of $11.2 \mathrm{mg} \%$ and packed cell volume of $32.6 \%$. Catering predominantly to Vokkaliga community in whom literature reports increased prevalence of BTT, addition of a cost effective test like NESTROFT in the antenatal panel, appears promising.

\section{Introduction}

At least $1.5 \%$ of the world's population are carriers of $\beta$-thalassemia trait (BTT) with 80 90 million patients and an estimated 60,000 new cases recognized each year. ${ }^{1}$ South east Asian region countries alone account for $50 \%$ of the world's carriers, ${ }^{2}$ carrier rates varying from $0-17 \%$ among different ethnic groups. ${ }^{3}$

Hence it is obvious that the prevention of thalassemia major can be reached by adopting screening programs to detect BTT individuals. The most efficient way of doing this has been found to be screening of pregnant women for possible BTT, so that prenatal diagnosis can be obtained by at risk couples. ${ }^{4}$

\section{Materials and Methods}

This was an observational study of 2 months duration done in the Departments of Pathology and Obstetrics and Gynecology. We studied 55 pregnant women attending the antenatal clinic of Kempegowda Institute of Medical Sciences, Bangalore. The aim of this study was to screen pregnant women for potential BTT by naked eye single tube osmotic fragility test (NESTROFT) and evaluate the frequency of NESTROFT positivity. An informed consent to participate in the study was taken. After noting down age and period of gestation, all the women were questioned, to know about their awareness of thalassemia and responses were recorded. About $2 \mathrm{~mL}$ of venous blood was collected in $\mathrm{K}_{3}$ ethylenediaminetetraacetic acid (1 $\mathrm{mg} / \mathrm{mL}$ ). Values of hemoglobin \%, packed cell volume (PCV) and blood group were noted down from their antenatal laboratory investigation chart. NESTROFT was performed according to the standard procedure on all the 55 samples as follows: a stock solution of $10 \%$ buffered saline was prepared by dissolving 90 $\mathrm{mg}$ of sodium chloride, $13.65 \mathrm{mg}$ of disodium hydrogen phosphate $\left(\mathrm{Na}_{2} \mathrm{HPO}_{4}\right)$ and $2.43 \mathrm{mg}$ of sodium dihydrogen phosphate $\left(\mathrm{NaH}_{2} \mathrm{PO}_{4}\right)$ in 1 $\mathrm{L}$ of distilled water and $\mathrm{pH}$ adjusted to 7.4. This stock solution was refrigerated. Whenever NESTROFT was scheduled, a 1\% solution was made from the stock solution [ 1 in 10 dilution with distilled water; $0.36 \%$ buffered saline was prepared by diluting $36 \mathrm{~mL}$ of $1 \%$ saline with 64 $\mathrm{mL}$ of distilled water to make $100 \mathrm{~mL} ; 2 \mathrm{~mL}$ of $0.36 \%$ buffered saline was taken in one test tube $(10 \times 1 \mathrm{~cm}$ diameter) labeled test and $2 \mathrm{~mL}$ of distilled water in another tube labeled control ]. A drop of test blood sample was added to each of the tubes and left undisturbed for half an hour at room temperature. After half an hour both tubes were shaken and then held against a white paper on which a thin black line is drawn. The black line should be clearly visible through the contents of the control tube. If the line was clearly visible through the contents of the tube labeled test, NESTROFT was considered negative. If the line was not clearly visible through the contents of the tube with $0.36 \%$ buffered saline, the test was considered positive.

\section{Principle of naked eye single tube osmotic fragility test}

A positive NESTROFT indicates that all red cells in the tested sample have not undergone lysis in $0.36 \%$ buffered saline. These unlysed red cells resulted in the hazy appearance of the contents of the tube and render the line on the paper indistinct. These red cells also sediment as a button at the bottom of the tube when it is left undisturbed for some time. Thus a positive NESTROFT indicates decreased red cell osmotic fragility and increased resistance to osmotic lysis.

\section{Results}

Among the 55 pregnant women $99 \%$ were
Correspondence: Shankaran Rukmini Niveditha Department of Pathology, Kempegowda Institute of Medical Sciences, BSK $2^{\text {nd }}$ stage, Bangalore 560070 , Karnataka, India.

Tel.: 91.9845485544.

E-mail: srniveditha@gmail.com

Key words: $\beta$-thalassemia trait, screening, NESTROFT, pregnancy.

Conflict of interest: the authors declare no potential conflict of interest.

Contributions: HS, tests conduction, data acquisition and analysis; SRN, study concept, data analysis, manuscript writing; SN, manuscript revising and contributing with valuable clinical inputs.

Funding: we acknowledge the Indian Council of medical research (ICMR) for having funded this project Under the STS project scheme for undergraduate medical students.

Conference presentation: this paper has been presented at the international undergraduate medical conference KARMIC - 2013 held at Kolkata, India.

Received for publication: 17 June 2014.

Revision received: 6 November 2014.

Accepted for publication: 29 January 2015.

This work is licensed under a Creative Commons Attribution 3.0 License (by-nc 3.0).

(C) Copyright H. Sarda et al., 2015

Licensee PAGEPress, Italy

Thalassemia Reports 2015; 5:4430

doi:10.4081/thal.2015.4430

unaware of thalassemia. Of the 55 screened for potential BTT, 12/55 were NESTROFT positive. Hence, frequency of NESTROFT positivity in pregnant women attending was $21.89 \%$, with $50 \%$ of the positives belonging to $21-25$ year age group. Most of the women in the study group i.e., 39/55 were in the III trimester and hence 6 out of 12 i.e. $50 \%$ positives were in the III trimester. Most of the women with NESTROFT positivity had lower hemoglobin between $9-11 \mathrm{~g} \%(\mathrm{P}=0.05)$ with a mean hemoglobin of $11.4 \mathrm{~g} \%$ and $\mathrm{PCV}$ of $32.6 \%(\mathrm{P}=0.005)$.

\section{Conclusions}

Unusually high percentage of NESTROFT positives was found in this study. This is comparable to a study by Colah et al. ${ }^{5}$ with $14 \%$ NESTROFT positivity, where they screened 61,935 pregnant women. In a few studies from Karnataka, Vokkaliga community has shown relatively high percentage of BTT when compared to other communities..$^{6,7}$ In a rural based study by our institute, screening of BTT was 
done in pregnant women by NESTROFT and the frequency of overall NESTROFT positivity was found to be $8.5 \% .{ }^{7}$ However when individual castes were considered $27.8 \%$ of NESTROFT positive pregnant women belonged to Vokkaliga community. ${ }^{7}$ As our hospital caters predominantly to this community we attribute this high percentage of NESTROFT positivity to the same.

We could not confirm the findings by $\mathrm{HbA}_{2}$ estimation but review of literature shows specificity of $94.12 \%$, sensitivity of $95.23 \%$, positive predictive value of $41.02 \%$ and negative predictive value of $99.78 \%,{ }^{8}$ while some have documented a sensitivity and negative predictive value of $100 \%$, specificity of $85.47 \%$ and positive predictive value of $66 \% .^{9}$ NESTROFT also happens to be a very economical test with less than Rupees $2 /$ test $^{7}$ and a high negative predictive value.,

As a pilot study in an urban hospital catering predominantly to Vokkaliga community this study demonstrates high frequency of NESTROFT positivity in pregnant women in this community elucidating the need for routine screening of all pregnant women with
NESTROFT combined with other red cell indices and $\mathrm{HbA}_{2}$ estimation.

So we propose the addition of NESTROFT for screening of BTT in pregnant women among the antenatal tests especially in high risk communities like the Vokkaligas especially in resource restricted countries like India.

\section{References}

1. Sachdev R, Dam AR, Tyagi G. Detection of $\mathrm{Hb}$ variants and hemoglobinopathies in Indian population using HPLC: a report of 2600 cases. IJPM 2010;5:57-62.

2. Old J, Galanello R, Eleftheriou A, et al. Prevention of thalassemias and other hemoglobin disorders, $2^{\text {nd }}$ ed. Vol. 1. Cyprus: Thalassemia International Federation Publication; 2013.

3. Ganja B, Charabarti S, Sengupta B. Prenatal diagnosis of thalassemia. Int $\mathrm{J}$ Hum Genet 2000;48:1082-84.

4. Varma IC, Saxena R, Kohli S. Past, present and future scenario of thalassemic case and control in India. IJPM 2011;134:507-21.

5. Colah R, Surve R, Wadia M, et al. Carrier screening of BTT during pregnancy in India - a 7 year evaluation. Genet Test 2008;12:181-5.

6. Mohanty D, Colah R, Gorashaker AC, et al. Prevalence of $\beta$-thalassemia and other haemoglobinopathies in six cities in India: a multicentre study. J Commun Genet 2013;4:33-42.

7. Kulkarni P, Masthi NRR, Niveditha SR, Suvarna R. The prevalence of BTT among pregnant women who attended the ANC clinic in a PHC, by using NESTROFT in Banglore, Karnataka. J Clin Diagn Res 2013;7:1414-7.

8. Chakrabarti I, Sinha SK, Ghosh N, Goswami BK. thalassemia carrier detection by NESTROFT: an answer in rural scenario. Iranian J Pathol 2012;7:19-26.

9. Piplani S, Mana R, Lalit M, et al. NESTROFT - a valuable, cost effective screening test for $\beta$ thalassemia trait in North Indian Punjabi population. J Clin Diagn Res 2013;7:2784-7. 